\title{
Maternal and perinatal outcome in severe preeclampsia and eclampsia
}

\section{Neha Saxena*, Amarjeet Kaur Bava, Yogeshwar Nandanwar}

Department of Obstetrics and Gynaecology, L.T.M.M.C. and L.T.M.G, Sion Hospital, Mumbai, Maharashtra, India

Received: 19 April 2016

Accepted: 13 May 2016

\author{
*Correspondence: \\ Dr. Neha Saxena, \\ E-mail: neha.sxn2011@gmail.com
}

Copyright: (c) the author(s), publisher and licensee Medip Academy. This is an open-access article distributed under the terms of the Creative Commons Attribution Non-Commercial License, which permits unrestricted non-commercial use, distribution, and reproduction in any medium, provided the original work is properly cited.

\begin{abstract}
Background: Pre-eclampsia accounts for the majority of referrals in a tertiary care centre as it stands one of the major causes of maternal and perinatal morbidity and mortality. The objective of this study was to study the maternal and fetal outcome in patients with severe pre-eclampsia and eclampsia in a tertiary centre over a period of one year.

Methods: Total 150 women with severe eclampsia and eclampsia after 20 weeks of gestation were included. Women with medical complications like anemia, preexisting hypertension, epilepsy, diabetes, vascular or renal disease, multiple gestation, polyhydramnios were excluded. Patients were managed as per existing protocol after proper history, examination and investigations. Anti-hypertensive of choice was alphamethyl-dopa, labetalol and oral nefidipene. Magnesium sulphate was used as anti convulsant.

Results: Out of 150 cases of severe pre-eclampsia and eclampsia, majority (69\%) were between 20-30 years of age and $47 \%$ were primigravida. We had 75 patients with convulsions on admission and 75 with severe pre-eclampsia of whom 11 had convulsions. Headache was most common complaint. Common mode of delivery was caesarean section in $72(48 \%)$ women, majority in view of failed induction or non-progress. Maternal complications were noted in $59 \%$ attributed to renal dysfunction, postpartum hemorrhage, DIC, placental abruption, HELLP, pulmonary edema, pulmonary embolism and renal failure. 4 maternal deaths were recorded.

Conclusions: Maternal and perinatal complications are more in patients with eclampsia. The incidence of eclampsia can be reduced by better antenatal care, early recognition and prompt treatment of severe pre-eclampsia.
\end{abstract}

Keywords: Pre-eclampsia, Eclampsia, Hypertension, Maternal morbidity and mortality

\section{INTRODUCTION}

Hypertension in pregnancy constitutes the most common medical complication occurring in $12-22 \%$ of all pregnancies of which pre-eclampsia remains the leading cause that complicates $10 \%$ of all pregnancies. ${ }^{1,2}$ It is defined as new onset of elevated blood pressure and proteinuria $(\mathrm{BP}>/=140 / 90$ and $>/=0.3 \mathrm{gm}$ protein in 24 hours urine specimen) after 20 weeks of gestation in a previously normotensive woman. ${ }^{3,4}$ It is considered severe if blood pressure and proteinuria are increased substantially $(\mathrm{BP}>/=160 / 110$ and $>5 \mathrm{gm}$ protein in 24 hours urine specimen) or symptoms of end organ damage like thrombocytopenia, altered liver function, oliguria, cerebral or visual disturbances, pulmonary edema and fetal growth restriction are present.

Eclampsia is defined as the new onset of generalized tonic clonic seizure in a woman with severe preeclampsia. Seizures most commonly occur in the postnatal period in $44 \%$ cases, antenatally in $38 \%$ and in the intrapartum period in $18 \% .^{5}$

It was found that $3-5 \%$ of first pregnancies and $1 \%$ of subsequent pregnancies are complicated by preeclampsia. ${ }^{1}$ WHO estimated that approximately 60,000 women die each year from pre-eclampsia world-wide. Pre-eclampsia and eclampsia account for $24 \%$ of all 
maternal deaths in India, mainly attributed to complications like accidental haemorrhage, disseminated intravascular coagulation, pulmonary edema, cardiac failure, HELLP syndrome, renal failure, adult respiratory distress syndrome and cerebral hemorrhage. ${ }^{6}$ Preeclampsia is a multisystem disorder where release of one or more factors damage the vascular endothelial cells throughout the maternal circulation leading to multisystem dysfunction. ${ }^{7}$ There is currently no single cost effective and reliable screening test for preeclampsia and there are no well-established measures for primary prevention.

The ultimate treatment for pre-eclampsia to prevent potential maternal complications is to deliver the patient. However, delivery is not always in best interest of fetus. The rationale for delaying delivery in these pregnancies, is to reduce perinatal morbidity and mortality by delivery of more mature fetus and to lesser degree to achieve more favourable cervix..$^{8-10}$

Access to perinatal care, early detection of the disorder, careful monitoring and appropriate management are crucial elements in prevention of pre-eclampsia related deaths. Pre-eclampsia is associated with increased risk of disseminated intravascular coagulation, placental abruption, hepatic failure, acute renal failure, cerebrovascular and cardiovascular complications, pulmonary edema, HELLP syndrome, eclampsia, retinal detachment, aspiration pneumonia and maternal death. Fetal morbidities include preterm delivery, small for gestation, intrauterine growth restriction (IUGR), still births, low birth weight babies. ${ }^{6,11}$

The term "eclampsia" is derived from a Greek word meaning "like a flash of lightening". Alexander Hamilton (1781) described eclampsia as a disease which always attended with the utmost hazard and frequently kills the woman like a fit of apoplexy. Eclampsia; a complication of preeclampsia is a life threatening emergency that continues to be a major cause of maternal and perinatal morbity and mortality worldwide. According to Doeley's estimation, globally about 50,000 women die of eclampsia annually. Majority of these deaths occur in developing countries and most of these are preventable. ${ }^{12}$

In India, maternal mortality and morbidity from eclampsia is very high. The figure ranges from $8-14 \%$. The perinatal mortality ranges from $14.6 \%$ to $47.4 \%{ }^{13,14}$

The incidence of eclampsia can be reduced by better antenatal care, early recognition and prompt treatment of severe pre-eclampsia. ${ }^{15,16}$

For ignorant or undiagnosed patients who present with convulsions, we can offer emergency services which will definitely help to reduce both maternal and perinatal mortality due to eclampsia. The clinical management of eclampsia has gone through many changes and achieved good results with the introduction of various treatment regimes. $^{16}$

Ours being a tertiary care centre, receives many complicated cases as emergency from peripheral, maternity clinics and nursing homes. The present study is undertaken to find out maternal and perinatal mortality and morbidity rate in severe pre-eclampsia and eclampsia; also to identify the factors influencing maternal and perinatal outcome.

\section{METHODS}

The present study is prospective study carried out on 150 pregnant women of severe pre-eclampsia and eclampsia with more than 20 weeks of gestation who were admitted from $1^{\text {st }}$ January 2014 to $31^{\text {st }}$ December 2014 in our tertiary centre. Patients with medical complications like anaemia, preexisting hypertensive, diabetes, vascular or renal disease, multiple gestation, polyhydramnios, GTN were excluded from the study. The outcome of each pregnancy was obtained by examining the patient in labour ward and neonates in neonatal intensive care unit.

On admission detailed demographic, personal, medical, obstetric and family history was recorded from the patient or her attendant as appropriate. General physical examination, systemic, abdominal and pelvic examinations were carried out. Investigations like complete blood count with absolute platelet count, liver function tests, renal function tests, coagulation profile, and fundoscopy and urine examination were performed for all patients. Ultrasound was done at the time of admission after patient stabilization. Obstetric management was carried out as per department protocol. Corticosteroids were administered if gestational age was less than 34 weeks gestation. The decision regarding timing and mode of delivery were individualized. Eclamptic patients were given magnesium sulphate by Pritchard's regimen; anti-hypertensive drugs were nifedipine, methyldopa, and labetalol singly or in combination. Obstetric management was done (spontaneous/ induced labor) as per the unit protocols and patients were delivered either by vaginal route or by cesarean section. Neonatal care was provided by pediatrician from delivery onwards. The patients with uncontrolled hypertension were managed in collaboration with physician and anesthetist.

All the mothers were followed up for evidence of change in BP and to look for other complications of eclampsia for 6 weeks. All the babies delivered were followed up during early neonatal period for complications. Maternal and perinatal complications were noted down. At the end of the study, the data was compiled and analyzed.

\section{RESULTS}

Out of 150 patients, 75 patients were referred for convulsions. Headache was the main symptom in 66 
patients of severe pre-eclampsia. 11 patients of severe pre-eclampsia later on had convulsions. (8 were antepartum and 3 were postpartum). Edema feet were noted in 37 patients. Others presented with vomiting, blurring of vision, oliguria and epigastric pain.

Table 1: Symptomatology.

\begin{tabular}{|ll|}
\hline Symptoms & Cases \\
\hline Convulsions & $75+11$ \\
\hline Headache & 66 \\
\hline Vomiting & 23 \\
\hline Blurring of vision & 14 \\
\hline Epigastric pain & 11 \\
\hline Edema feet & 37 \\
\hline Oliguria & 13 \\
\hline Generalized edema/ascites & 03 \\
\hline High blood pressure & 14 \\
\hline
\end{tabular}

Table 2: Age distribution.

\begin{tabular}{|lll|}
\hline Years & Cases & Percentage \\
\hline$<20$ & 08 & 5.3 \\
\hline $21-25$ & 58 & 38.7 \\
\hline $26-30$ & 46 & 30.7 \\
\hline $31-35$ & 14 & 9.3 \\
\hline$>35$ & 24 & 16 \\
\hline
\end{tabular}

We had $104(69 \%)$ patients between 20-30 years of age followed by $16 \%$ patients beyond 35 years of age.
Table 3: Parity.

\begin{tabular}{|ll|l|}
\hline Parity & Cases & Percentage \\
\hline Primigravida & 70 & 46.6 \\
\hline Multigravida & 46 & 30.7 \\
\hline Grand multipara & 34 & 22.7 \\
\hline
\end{tabular}

Majority (46.6\%) of our patients were primigravidae.

Table 4: Antenatal care.

\begin{tabular}{|lll|}
\hline Antenatal care & Cases & Percentage \\
\hline Unbooked/transferred & 88 & 58.7 \\
\hline Booked & 62 & 41.3 \\
\hline
\end{tabular}

More than half of the patients in our study (59\%) were unbooked/transferred.

Table 5: Gestational age.

\begin{tabular}{|lll|}
\hline Gestational age & Cases & Percentage \\
\hline$<30$ & 10 & 6.7 \\
\hline $31-37$ & 96 & 64 \\
\hline $38-40$ & 34 & 22.6 \\
\hline$>40$ & 10 & 6.7 \\
\hline
\end{tabular}

Majority patients (64\%) presented before 37 completed weeks of gestation, followed by those presenting up to 40 weeks of gestation.

Table 6: Investigations.

\begin{tabular}{|llllllll|}
\hline Proteinuria & Cases & RFT & Case & LFT & Cases & Coag study & Cases \\
\hline$</=+1$ & $26(17.3 \%)$ & BUN $>40$ & $29(19.3 \%)$ & SGOT $>100$ IU & $18(12 \%)$ & Haemoglobin<9 & $23(15.3 \%)$ \\
\hline$>/=+2$ & $28(18.67 \%)$ & Creat $>1$ & $47(31.3 \%)$ & SGPT $>100$ IU & $18(12 \%)$ & Platelets $<50,000$ & $05(3.3 \%)$ \\
\hline$>/=+3$ & $96(64 \%)$ & 0liguria & $12(8 \%)$ & & & Bilirubin $>4$ & $05(3.3 \%)$ \\
\hline
\end{tabular}

Liver functions were deranged in $24 \%$ of our cases out of which $17.3 \%$ cases had SGOT> 100 IU and another $18.67 \%$ cases had SGPT>100 IU. Renal functions were deranged in $59 \%$ of our patients, who most commonly had raised serum creatinine levels.

Table 7: Pregnancy outcome.

\begin{tabular}{|llc|}
\hline Mode of delivery & Cases & Percentage $(n=149)$ \\
\hline Vaginal & 55 & 37 \\
\hline LSCS & 63 & 42.3 \\
\hline Instrumental & 22 & 14.8 \\
\hline Hysterotomy & 09 & 6 \\
\hline
\end{tabular}

The mode of delivery in these patients was determined on the basis of fetal condition, gestational age and bishops score. Labor induction was done after assessing the above factors. Our study showed that LSCS was performed in majority patients $(42.3 \%)$ in view of failed induction or non-progress. However, $37 \%$ patients delivered vaginally.

Table 8: Indications of LSCS.

\begin{tabular}{|lll|}
\hline Indication & Cases & Percentage \\
\hline Failure of induction & 34 & 47 \\
\hline Fetal distress & 17 & 23.6 \\
\hline IUGR/doppler changes & 09 & 12.5 \\
\hline CPD & 08 & 11 \\
\hline Abruption & 04 & 5.5 \\
\hline
\end{tabular}

Most common indication for operative intervention was failed induction or non-progress followed by fetal distress in our study. 
Table 9: Convulsion delivery interval.

\begin{tabular}{|ll|}
\hline C-D interval (hours) & Cases \\
\hline $6-12$ & $16+7$ \\
\hline $13-24$ & $44+1$ \\
\hline$>24$ & 14 \\
\hline Total & $\mathbf{7 4 + 8}$ \\
\hline
\end{tabular}

45 patients with eclampsia delivered between 13-24 hours after first convulsion. However, 23 patients delivered within 6-12 hours of the first convulsion.

One patient expired antenatally due to acute kidney injury and HELLP.

Table 10: Maternal complications.

\begin{tabular}{|lll|}
\hline Maternal complication & Cases & Maternal death \\
\hline Abruptio placentae & 10 & \\
\hline Pulmonary edema & 04 & 01 \\
\hline Pulmonary embolism & 02 & 01 \\
\hline Renal dysfunction & 12 & \\
\hline HELLP & 05 & 01 \\
\hline DIC & 18 & 01 \\
\hline PPH & 38 & \\
\hline Mortality & 04 & \\
\hline
\end{tabular}

Maternal complications like PPH occurred in 38 cases followed by DIC in 18, renal dysfunction in 12, abruption in 10, HELLP in 5, Pulmonary edema in 4, Pulmonary embolism in 2 . There were 4 maternal deaths.

Table 11: Maternal complications and comparison.

\begin{tabular}{|llll|}
\hline $\begin{array}{l}\text { Maternal } \\
\text { complication }\end{array}$ & Cases & $\begin{array}{l}\text { Singh SR } \\
\text { et al }\end{array}$ & $\begin{array}{l}\text { Shaikh S } \\
\text { et al }\end{array}$ \\
\hline Abruptio placentae & 10 & 01 & 09 \\
\hline Pulmonary edema & 04 & 08 & 00 \\
\hline Pulmonary embolism & 02 & 04 & 01 \\
\hline Renal dysfunction & 12 & 09 & 02 \\
\hline HELLP & 05 & 02 & 02 \\
\hline DIC & 18 & 02 & 01 \\
\hline PPH & 38 & 31 & 00 \\
\hline Mortality & 04 & 08 & 00 \\
\hline
\end{tabular}

Table 12: Perinatal outcome.

\begin{tabular}{|ll|}
\hline Total cases & 150 \\
\hline Total no of babies & 149 \\
\hline Total no of live births & 113 \\
\hline Total no of IUFD & 21 \\
\hline Total no of FSB & 09 \\
\hline Total no of neonatal deaths & 15 \\
\hline Total no of perinatal deaths & $45(21+09+15)$ \\
\hline
\end{tabular}

Perinatal mortality was seen in 45 cases (30\%) which included IUFD in 21, FSB in 9 and neonatal deaths in 15.

Neonatal deaths were mostly due to extreme prematurity and its complications.

Table 13: Comparison of maternal and perinatal outcome.

\begin{tabular}{|llll|}
\hline $\begin{array}{l}\text { Maternal } \\
\text { complication }\end{array}$ & $\begin{array}{l}\text { Pre- } \\
\text { eclampsia }\end{array}$ & Eclampsia & Total \\
\hline Abruption & 08 & 02 & 10 \\
\hline HELLP & 03 & $02(1$ expired $)$ & 05 \\
\hline $\begin{array}{l}\text { Renal } \\
\text { dysfunction }\end{array}$ & 02 & 07 & 09 \\
\hline $\begin{array}{l}\text { Pulmonary } \\
\text { edema }\end{array}$ & 01 & $03(1$ expired $)$ & 04 \\
\hline $\begin{array}{l}\text { Pulmonary } \\
\text { embolism }\end{array}$ & 00 & $02(1$ expired $)$ & 02 \\
\hline PPH & 28 & 10 & 38 \\
\hline $\begin{array}{l}\text { DIC } \\
\text { Convulsions }\end{array}$ & $8+3$ & 03 & 18 \\
\hline Death & 01 & 03 & 14 \\
\hline
\end{tabular}

Thus it is evident from the above table that patients of eclampsia had more complications as compared to severe pre-eclampsia.

There was poor perinatal outcome in both the groups; that is perinatal loss was seen in $30 \%$ of the cases.

\section{DISCUSSION}

During the study period, there were 27,755 obstetric admissions including 150 cases of severe pre-eclampsia and eclampsia.

Out of 150 patients, 75 patients were referred from other institutions with convulsions for appropriate obstetric management. We report headache as the main symptom in 66 patients of severe pre-eclampsia. However, 11 patients of severe pre-eclampsia later on developed convulsions ( 8 were antepartum and 3 were postpartum), followed by edema feet, vomiting, blurring of vision oliguria and epigastric pain in the rest.

A study done by Singhal SR et al showed that $44 \%$ patients in their study had headache as the main symptom. $^{17}$

In our study, we report convulsions in 83 patients. However, similar study done by Singhal SR et al showed that $51 \%$ of patients had presented with convulsions. ${ }^{17}$

More than half of the patients in our study (59\%) were unbooked/transferred, a finding that correlates with the study done by Shaikh $\mathrm{S}$ et al who had $82 \%$ patients unbooked/transferred. ${ }^{18}$ 
Most of the patients $104(69 \%)$ were falling in the age group between 20-30 years. Similar findings were obtained from reports of Nishtar hospital Multan. ${ }^{19}$

Also study done by Singhal SR et al showed that $90 \%$ patients were less than 30 years of age. ${ }^{17}$

It was found that $46.6 \%$ patients were primigravidas. The findings are in good agreement with observations in a study by Shaikh $\mathrm{S}$ et al. Another study done by SR Singhal et al showed that $73 \%$ patients were Primigravidas. $^{17}$

Ketz et al reported $70 \%$ of their patients as primigravidas. ${ }^{20}$

$64 \%$ of cases had gestational age between 31 to 37 weeks and $35 \%$ of patients had term pregnancy. The findings are in good agreement with Shaikh $\mathrm{S}$ et al and Mohammad Tariq.

Liver functions were deranged in $24 \%$ of our cases and renal functions were deranged in another $59 \%$ whereas in a study done by Singhal SR et al showed that $20 \%$ patients had deranged liver function tests while $27 \%$ patients had deranged renal functions. ${ }^{17}$

$15 \%$ patients had low haemoglobin which was due to complications like abruption placentae, DIC and HELLP. $3 \%$ patients also had elevated bilirubin and low platelet counts. PT INR was deranged in $12 \%$ patients who were managed by giving FFP transfusions.

There was increased incidence of operative delivery $(48 \%)$ in these patients. The mode of delivery in these patients was determined on the basis of fetal condition, gestational age and bishops score. Labor induction was done after assessing the above factors. A study by Shaikh $\mathrm{S}$ et al showed caesarean rate of $73 \%$ and vaginal delivery in $26.7 \%$. One patient died antenatally due to HELLP with acute kidney injury.

Most common indication for operative intervention was failed induction or non-progress followed by fetal distress in our study where as it was uncontrolled blood pressure and fetal distress in the study by Shaikh $\mathrm{S}$ et al.

45 patients with eclampsia delivered between 13-24 hours after first convulsion.

Maternal complications included $\mathrm{PPH}$ in 38 cases followed by DIC in 18, renal dysfunction in 12, abruption in 10, HELLP in 5, Pulmonary edema in 4, Pulmonary embolism in 2 and maternal death in 4 cases.

Abruption was seen in 9 cases in the study by Shaikh $\mathrm{S}$ et al and Murphys DJ. Whereas another study done by Singhal SR et al showed only one case had abruption.
Perinatal mortality was seen in 45 cases (30\%) which included IUFD in 21, FSB in 9 and neonatal deaths in 15. Study by Shaikh $\mathrm{S}$ et al showed IUD in 14, neonatal death in 18 cases and perinatal loss of $38.6 \%$. Neonatal deaths were mostly due to extreme prematurity and its complications.

Thus patients of eclampsia had more dreadful complications as compared to severe pre- eclampsia. These findings are in good agreement with observations by study done by Singhal SR et al.

There was poor perinatal outcome in both the groups; that is perinatal loss was seen in $30 \%$ of the cases.

\section{CONCLUSION}

Pre-eclampsia and eclampsia still remains a major problem in developing countries. It is one of the important causes of maternal and perinatal morbidity and mortality probably resulting from inadequate and suboptimal antenatal care and lack of education and awareness amongst people belonging to low socioeconomic status. Both maternal and perinatal mortality rate are still disappointing. One maternal death occurs in every 25 ecliptic women. This situation demands extension of medical services in rural areas for the benefit of both mother and the baby.

Good antenatal care will identify preeclampsia in early stages.

A moderate reduction of death of mother and fetus in our institution was possible due to wider use of magnesium sulphate, timed delivery, and proper implementation of emergency obstetric care facilities to mother with eclampsia.

The incidence of eclampsia can be reduced by better antenatal care, early recognition and prompt treatment of severe pre-eclampsia.

For ignorant or undiagnosed patients who present with convulsions, we can offer emergency services which will definitely help to reduce both maternal and perinatal mortality due to eclampsia.

Adequate assessment, investigation, monitoring and intensive care for these women in the antepartum, intrapartum and postpartum period and timely delivery improve significantly the maternal and perinatal outcome. Regular blood pressure monitoring specially in predisposed individuals is essential to detect such high cases early and thus prevent complications. This can be done with the help of family physicians.

Funding: No funding sources

Conflict of interest: None declared

Ethical approval: Not required 


\section{REFERENCES}

1. Carty DM, Delles C, Dominiczak AF. Preeclampsia and future maternal health. J Hypertens. 2010;28:1349-55.

2. Duley L. The global impact of pre-eclampsia and eclampsia. Semin Perinatol. 2009;33:130-7.

3. Sibai B, Dekker G, Kupferminc M. Pre-eclampsia. Lancet. 2005;365(9461):785-99.

4. Tan KH, Kwek K, Yeo GS. Epidemiology of preeclampsia and eclampsia at the KK women's and children's hospital, Singapore. Singapore Med J. 2006;47(1):48-53.

5. Sibai BM. Diagnosis, prevention, and management of eclampsia. Obstet Gynecol. 2005;105(2):402-10.

6. Alvarez Navascués R, Marín R. Severe maternal complications associated with pre-eclampsia: an almost forgotten pathology? Nefrologia. 2001;21(6):565-73.

7. Roberts JM. Endothelial dysfunction in preeclampsia. Semin Reprod Endocrinol. 1998;16:5-15.

8. Multidisciplinary management of severe preeclampsia (PE) experts' guidelines 2008. Société française d'anesthésie et de réanimation. Collège national des gynécologues et obstétriciens français. Société française de médecine périnatale. Société française de néonatalogie. Ann Fr Anesth Reanim. 2009;28:275-81.

9. Pottecher T, Luton D. Prise en charge multidisciplinaire de la prééclampsie. French. Issy Les Moulineaux, France: Elsevier; Masson SAS; 2009.

10. Minire A, Mirton M, Imri V, Lauren M, Aferdita M. Maternal complications of preeclampsia. Med Arch. 2013;67(5):339-41.
11. Churchill D, Perry IJ, Beevers DG. Ambulatory blood pressure in pregnancy and fetal growth. Lancet. 1997;349:7-10.

12. Kuklina EV, Ayala C, Callaghan WM, et al. Hypertensive disorders and severe obstetric morbidity in the United States. Obstet Gynecol. 2009;113:1299-306.

13. Odendaal HJ, Pattinson RC, Bam R, Grove D, Kotze JVWT. Aggressive or expectant management for patients with severe preeclampsia between 28-34 weeks' gestation: a randomized controlled trial. Obstetrics and Gynecology. 1990;76(6):1070-5.

14. Duley L. Pre-eclampsia and the hypertensive disorders of pregnancy. British Medical Bulletin. 2003;67:161-76.

15. World Health Organization Fact Sheet; 2012.

16. Lack of preeclampsia awareness increases risk of infant mortality, press release, preeclampsia foundation; 2008.

17. Singhal S, Deepika, Anshu, Nanda S. Maternal and perinatal outcome in severe pre-eclampsia and eclampsia. South Asian Federation of Obstetrics and Gynecology. 2009;1(3):25-8.

18. Shaikh S, Ruby AJ, Piotrowski M. Pre eclampsia related chorioretinopathy with Purtscher's likefindings and macular ischaemia. Retina. 2003;23:247-50.

19. Naseer D, Ataullah K, Nudrat E. Perinatal and maternal outcome of eclamptic patients admitted in Nishtar Hospital, Multan. J Coll Physician Surg Pak. 2000;10:261-4.

20. Katz VL, Farmer R, Kuller JA. Pre-eclampsia into eclampsia: toward a new paradigm. Am J Obstet Gynecol. 2000;182:1389- 96.

Cite this article as: Saxena N, Bava AM,

Nandanwar Y. Maternal and perinatal outcome in severe preeclampsia and eclampsia. Int J Reprod Contracept Obstet Gynecol 2016;5: 2171-6. 